\title{
Optimalisasi Penggunaan Alat Berat pada Proyek Jalan Desa Sawah - Kayu Aro di Kabupaten Kampar
}

\author{
Eka Saputra $^{1}$, Fadrizal Lubis ${ }^{2}$, Winayati ${ }^{3}$ \\ 1,2,3 Program Studi Teknik Sipil, Fakultas Teknik, Universitas Lancang Kuning \\ Jl. Yos Sudarso km. 8 Rumbai, Pekanbaru, Telp. (0761) 52324 \\ Email: eka@ft.unilak.ac.id, fadrizal@unilak.ac.id, winayati@unilak.ac.id
}

\begin{abstract}
ABSTRAK
Pemerintah Pusat melalui Kementerian Keuangan menganggarkan dana alokasi khusus (DAK) penugasan bidang jalan (peningkatan jalan) tahun anggaran 2017 kepada Pemerintah Daerah Kabupaten Kampar yang salah satu dari dana alokasi khusus (DAK) tersebut oleh Pemerintah Daerah Kabupaten Kampar digunakan untuk peningkatan jalan Desa Sawah - Kayu Aro, kelas jalan tipe III, panjang jalan 4,1 $\mathrm{km}$, lebar jalan $5 \mathrm{~m}$, tebal perkerasan $4 \mathrm{~cm}$ dan jenis perkerasan jalan lentur di Kecamatan Kampar Utara Kabupaten Kampar namun pada saat proses pelaksanaan pekerjaan dilapangan terdapat berbagai kendala diantaranya yaitu antara lokasi proyek dan lokasi quarry, pabrik base berjarak $35 \mathrm{~km}$ jadi cukup jauh sementara truk bertonase besar tidak bisa masuk ke area atau lokasi proyek melewati jalan desa dengan kelas jalan tipe III lebar $2,5 \mathrm{~m}$ dan tebal perkerasan hanya $3 \mathrm{~cm}$. Tujuan penelitian ini adalah untuk mempercepat pelaksanaan proyek dan menghitung kebutuhan alat berat yang optimal pada pekerjaan penimbunan dan penghamparan base B dan base A terhadap biaya dan waktu. Metode yang digunakan pada penelitian ini adalah deskriptif, yang mana perhitungan dilakukan sesuai dengan kapasitas dan kemampuan alat berat yang dipergunakan dengan sebelum dan sesudah alternatif, dalam perhitungan dengan sebelum dan sesudah alternatif yang optimal pada penelitian ini adalah pada alternatif II dengan biaya Rp. 2.454.248.807,59 dan dengan jumlah hari kerja sebanyak 48 hari, paling ekonomis dan dengan waktu yang relatif lebih cepat dari alternatif lainnya sehingga alternatif II layak untuk direalisasikan.
\end{abstract}

Kata Kunci: Alat, Efektifitas, Efisiensi, Komposisi.

\begin{abstract}
The Central Government, through the Ministry of Finance, budgeted special allocation funds (DAK) for the assignment of road (road improvement) in 2017 fiscal year to Kampar Regency Government, one of the special allocation funds (DAK) of Kampar Regency Government was used to improve Sawah-Kayu Aro Village, type III road class, road length of $4.1 \mathrm{~km}$, road width of $5 \mathrm{~m}$, pavement thickness of $4 \mathrm{~cm}$ and type of flexible road pavement in Kampar Utara District, Kampar Regency, but during the field implementation process, there were various obstacles including the project location and the location of the quarry, the base manufactory was $35 \mathrm{~km}$ away, while the large tonnage truck cannot enter the project area or location through the village road with type III road class $2.5 \mathrm{~m}$ wide and pavement thickness was only 3 $\mathrm{cm}$. The purpose of this research is to accelerate the implementation of the project and calculate the optimal heavy equipment requirements for on base B and base A land filling and dumping work toward costs and time. The method used in this study is descriptive, in which the calculation is carried out relating with the capacity and capability of the heavy equipment used before and after alternatives, in the calculation with before and after the optimal alternative, the cost of this study on the alternative II is Rp. 2,454,248,807.59 and with a total of 48 working days, it is the most economical and a relatively faster time than other alternatives so that the alternative II is feasible to be realized.
\end{abstract}

Keywords: Equipment, Effectiveness, Efficiency, Composition 


\section{PENDAHULUAN}

Salah satu nawacita Presiden Republik Indonesia Joko Widodo adalah membangun infrastruktur jalan baru sepanjang 2.000 kilometer dan memperbaiki jalan di Sumatera, Jawa, Kalimantan, Sulawesi dan Papua untuk meningkatkan produktivitas rakyat dan daya saing dipasar internasional sehingga bangsa indonesia bisa maju dan bangkit bersama bangsa - bangsa Asia lainnya (Polmas, 2014).

Untuk mendukung program Presiden tersebut maka Pemerintah Pusat melalui Kementerian Keuangan menganggarkan dana alokasi khusus (DAK) penugasan bidang jalan (peningkatan jalan) tahun anggaran 2017 kepada Pemerintah Daerah Kabupaten Kampar yang salah satu dari dana alokasi khusus (DAK) tersebut oleh Pemerintah Daerah Kabupaten Kampar digunakan untuk peningkatan jalan Desa Sawah - Kayu Aro, kelas jalan tipe III, panjang jalan $4,1 \mathrm{~km}$, lebar jalan $5 \mathrm{~m}$, tebal perkerasan $4 \mathrm{~cm}$ dan jenis perkerasan jalan lentur di Kecamatan Kampar Utara Kabupaten Kampar. Dengan nilai kontrak

Rp. 13.143.081.000,- ( tiga belas milyar seratus empat puluh tiga juta delapan puluh satu ribu rupiah) dan jangka waktu pelaksanaan proyek 180 (seratus delapan puluh) hari kalender terhitung mulai tanggal 05 Juni 2017 sampai dengan tanggal 01 Desember 2017 dengan progres proyek saat dilakukan tinjauan berada pada angka $41,10 \%$ tepatnya pada minggu ke 2 (dua) bulan september tahun 2017.

Namun pada saat proses pelaksanaan pekerjaan dilapangan terdapat berbagai kendala diantaranya yaitu antara lokasi proyek dan lokasi quarry, pabrik Base ber jarak $35 \mathrm{~km}$ jadi cukup jauh sementara truk bertonase besar tidak bisa masuk ke area atau lokasi proyek melewati jalan desa dengan kelas jalan tipe III lebar 2,5 $\mathrm{m}$ dan tebal perkerasan hanya $3 \mathrm{~cm}$. Akibatnya pihak kontraktor pelaksana harus mempergunakan truk bertonase kecil dengan komposisi alat berat yang digunakan pada proyek ini, berdasarkan data pemakaian alat berat, kendaraan dan hasil survei dilapangan yaitu 8 unit dump truck mitsubishi FE 74 kapasitas berat kosong 4,9 ton dan kapasitas volume 4,73 $\mathrm{m}^{3}, 1$ unit motor grader, 1 unit vibro roller, 1 unit water tank truck, 1 unit wheel loader dan 1 unit backhoe. Durasi waktu pekerjaan timbunan pilihan sesuai dengan schedule kontrak dilakukan selama 6 minggu atau 44 hari kerja Dengan data tersebut peneliti tertarik untuk meneliti seberapa besar optimalisasi penggunaan alat berat pada pekerjaan timbunan dan penghamparan Base B dan Base A untuk proyek peningkatan jalan Desa Sawah - Kayu Aro Panjang 4,1 kilometer dan Lebar 5 meter di Kecamatan Kampar Utara Kabupaten Kampar. Karena alat berat yang digunakan saling berhubungan dan saling mempengaruhi satu sama lainnya dalam bekerja. Sehingga sangat menentukan keberhasilan kontraktor dalam menyelesaikan pekerjaan yang tepat waktu dan biaya serta sesuai dengan kualitas yang disyaratkan.

\section{METODE PENELITIAN}

Penelitian ini dilaksanakan pada program pembangunan jalan dan jembatan propinsi Riau dan tepatnya pada peningkatan jalan Desa Sawah - Kayu Aro Panjang 4,1 Kilometer dan Lebar 5 Meter di Kecamatan Kampar Utara Kabupaten Kampar. Lokasi tersebut tertera pada gambar 3.1.

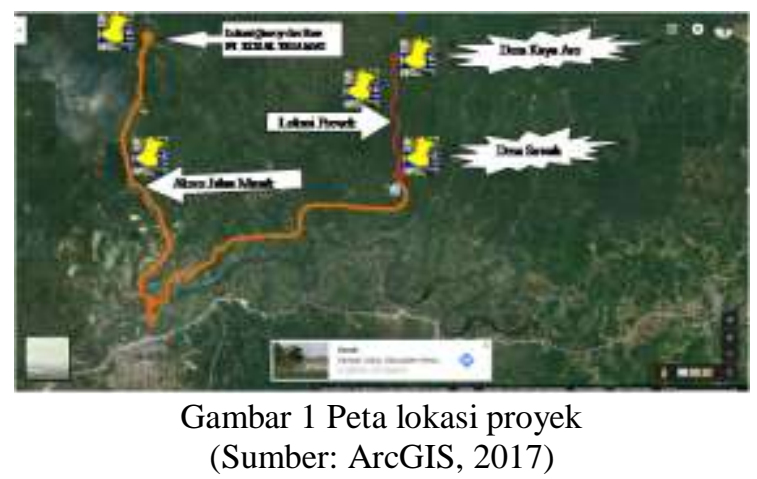

Waktu penelitian dimulai pada bulan Agustus 2017 dengan mempersiapkan proposal dan rencana kerja serta diperkirakan berakhir pada bulan Desember 2017 dengan kegiatan seminar hasil penelitian. Data penelitian di kumpulkan dari pihak terkait dan kondisi terakhir dilihat langsung ke lapangan. Selanjutnya data-data yang diperoleh dianalisis dan dituangkan dalam bentuk tugas akhir.

\section{Pengumpulan dan Cara Analisis Data}

\section{a. Pengumpulan data penelitian}

Data-data dikumpulkan dengan beberapa cara, mulai dari pengumpulan data dilapangan, mempelajari masalah yang diangkat, dan mencari informasi tambahan dengan mengajukan berbagai pertanyaan kepada narasumber. Data-data yang dikumpulkan selanjutnya diolah guna menyelesaikan penelitian ini. Data-data tersebut dapat dikelompokkan menjadi dua kelompok yang terdiri dari :

1) Data primer :

merupakan data-data yang diperoleh dari sumber pertama berupa catatan hasil observasi. Data-data primer yang dikumpulkan pada penelitian ini terdiri dari :

a) Catatan hasil observasi

Dilakukan dengan cara mendatangi lokasi proyek dan selanjutnya mencatat hasil pengamatan secara umum tentang situasi dan kondisi pelaksanaan proyek terutama 
kegiatan alat berat yang mengerjakan pekerjaan penimbunan pada jalan dimaksud

b) Catatan hasil wawancara dengan pihak terkait.

Dilakukan dengan pihak-pihak yang terlibat dengan pelaksanaan proyek.

c) Studi literatur

Cara ini dilakukan dengan mempelajari berkas-berkas perencanaan yang ada pada Dinas Pekerjaan Umum dan Penataan Ruang Kabupaten Kampar dan selanjutnya mencocokkannya dengan hasil observasi langsung. Selain itu juga dilakukan survey terhadap harga jual atau sewa alat di daerah.

2) Data sekunder :

merupakan data olahan atau berasal dari data primer yang telah diolah lebih lanjut dan disajikan atau oleh pihak lain. Biasanya data sekunder ditampilkan dalam bentuk tabel-tabel atau diagramdiagram. Data tersebut berupa :

a) Data perencanaan proyek

b) Daftar harga, indeks, kapasitas dan sewa peralatan

c) RAB

\section{b. Data penelitian}

Kondisi tanah yang terdapat pada lokasi proyek adalah rawa gambut. Kontur tanah yang berbukit dan lembah memerlukan usaha perataan agar sesuai dengan elevasi yang direncanakan. Pekerjaan yang akan dilakukan meliputi penggalian tanah yang berbukit yang akan ditimbunkan pada daerah yang rendah. Sehingga tercapai elevasi badan jalan yang direncanakan.

Pekerjaan galian dan timbunan di lokasi proyek (sumber data dari dokumen kontrak proyek peningkatan jalan Desa Sawah - Kayu Aro Panjang 4,1 Kilometer dan Lebar 5 Meter di Kecamatan Kampar Utara Kabupaten Kampar) adalah sebagai berikut :

1) Total volume pekerjaan timbunan pilihan dari sumber galian $5326,11 \mathrm{~m}^{3}$

2) Total volume pekerjaan base $B$ dari stock pile $4.674 \mathrm{~m}^{3}$

3) Total volume pekerjaan base A dari stock pile $3290,25 \mathrm{~m}^{3}$

4) Galian untuk selokan dan drainase air $14.000 \mathrm{~m} 3$

5) Panjang jalan 4,1 Km dan lebar 5,00 meter

6) Jarak tempat pengambilan tanah timbun (quarry) adalah $\pm 35 \mathrm{Km}$ dari lokasi proyek

7) jarak tempuh dari pabrik base B dan base A sejauh $\pm 35 \mathrm{Km}$

8) Komposisi alat berat yang digunakan kontraktor adalah : 1 unit motor grader, 1 unit backhoe, 1 unit water tank truck, 1 unit vibro roller, 1 unit wheel loader dan 8 unit truk mitsubishi FE 74 kapasitas berat kosong 4,9 ton dan kapasitas volume 4,76 M3
9) Data existing alat berat yang digunakan pada proyek penimbunan dan penghamparan base B dan base A ini ( sumber data dari aset kendaraan dan alat berat PT. Tata Inti Sepakat anak perusahaan PT. Lutvindo Wijaya Perkasa ) Cara menganalisis data

Penelitian dilakukan menggunakan metode deskriptif, yang mana data penelitian dipaparkan dan kemudian dianalisis menggunakan rumus-rumus tertentu. Perhitungan dilakukan sesuai dengan kapasitas dan kemampuan alat berat yang dipergunakan pada penimbunan dan penghamparan base B dan base A proyek peningkatan jalan Desa Sawah - Kayu Aro Panjang 4,1 Kilometer dan Lebar 5 Meter di Kecamatan Kampar Utara Kabupaten Kampar. PUPR (2016) rumus-rumus yang digunakan adalah :

\section{Backhoe}

Kapasitas produksi/jam,

$$
Q=\frac{V \times F_{b} \times F_{a} \times 60}{T_{s 1} x F v}
$$

Keterangan :

$\mathrm{V}=$ Kapasitas bucket; $\left(\mathrm{m}^{3}\right)$

$\mathrm{F}_{\mathrm{b}}=$ Faktor efisiensi alat

$\mathrm{F}_{\mathrm{v}}=$ Faktor konversi galian

T1 = Lama menggali, memuat, lain - lain (standar), (maksimum 0.32); menit

$\mathrm{T}_{2}=$ Lain - lain (standar), maksimum 0.10; (menit)

$\mathrm{T}_{\mathrm{s}}=$ Waktu siklus $\mathrm{Ts}=\mathrm{T} 1 \mathrm{x} \mathrm{fv}$

Koefisien alat $/ \mathrm{m}^{3}=1:$ Q1

2. Motor grader

a. Untuk pekerjaan perataan hamparan :

Kapasitas produksi/jam,

$Q=\frac{L_{h} x\left(n\left[b-b_{0}\right]+b_{0}\right) \times F_{a} \times 60}{N \times n \times T_{s}}$

Keterangan :

$\mathrm{L}_{\mathrm{h}} \quad$ = Panjang hamparan; $(\mathrm{m})$

$\mathrm{b}_{0} \quad=$ Lebar overlap; $(\mathrm{m})$

$\mathrm{F}_{\mathrm{a}} \quad=$ Faktor efisiensi kerja

$\mathrm{n} \quad=$ Jumlah lintasan; lintasan

$\mathrm{N}=$ Jumlah pengupasan tiap lintasan; kali lintasan

$\mathrm{v}=$ Kecepatan rata - rata; $(\mathrm{km} / \mathrm{h})$

$\mathrm{b} \quad=$ Lebar pisau efektif; $(\mathrm{m})$

$\mathrm{T}_{1} \quad$ = Waktu 1 kali lintasan $:\left(\mathrm{L}_{\mathrm{h}}\right.$ x 60$) /(\mathrm{v}$ x 1000); (menit)

$\mathrm{T}_{2}=$ Lain - lain; (menit)

$\mathrm{T}_{\mathrm{s} 3}=$ Waktu siklus,

$$
T_{s}=\sum_{n-1}^{n} T_{n} \text { (menit) }
$$

b) Pekerjaan perataan hamparan padat :

Kapasitas produksi/jam,

$$
Q=\frac{L_{h} x\left(n\left[b-b_{0}\right]+b_{0}\right) x F_{a} \times 60 x t}{N \times n \times T_{s} \times F_{k}}
$$

Keterangan : 
$\mathrm{F}_{\mathrm{k}} \quad=$ Faktor pengembangan bahan, $(\mathrm{m})$

$\mathrm{t} \quad=$ Tebal hamparan padat; diambil 0.15 $\mathrm{m} ;(\mathrm{m})$

c) Untuk pekerjaan pengupasan (grading) : Kapasitas produksi/jam,

$Q=\frac{L_{h} \times\left(n\left[b-b_{0}\right]+b_{0}\right) \times F_{a} \times 60}{N \times n \times T_{s}}$

Keterangan :

$\mathrm{L}_{\mathrm{h}} \quad$ = Panjang hamparan; $(\mathrm{m})$

$\mathrm{b}_{0} \quad=$ Lebar overlap; $(\mathrm{m})$

$\mathrm{F}_{\mathrm{a}} \quad$ Faktor efisiensi kerja

$\mathrm{n} \quad=$ Jumlah lintasan; lintasan

$\mathrm{N}=$ Jumlah pengupasan tiap lintasan; kali lintasan

$\mathrm{v}=$ Kecepatan rata $-\mathrm{rata} ;(\mathrm{km} / \mathrm{h})$

$\mathrm{b}=$ Lebar pisau efektif; $(\mathrm{m})$

$\mathrm{T} 1=$ Waktu 1 kali lintasan : $($ Lh x 60$) /(\mathrm{v} \mathrm{x}$ 1000); (menit)

$\mathrm{T}_{2}$ = Lain - lain; (menit)

$\mathrm{T}_{\mathrm{s} 3}=$ Waktu siklus,

$T_{s}=\sum_{n-1}^{n} T_{n}$

3. Vibro roller

Kapasitas produksi/jam,

$Q=\frac{(\operatorname{bexv} \times 1000) \times t \times f_{a}}{n}$

Keterangan :

$\mathrm{b}_{\mathrm{e}} \quad=$ Lebar efektif pemadatan $=\mathrm{b}-\mathrm{b}_{\mathrm{o}}$ (overlap); (m)

$\mathrm{b} \quad=$ Lebar efektif pemadatan; $(\mathrm{m})$

$\mathrm{b}_{0} \quad=$ Lebar overlap; $(\mathrm{m})$

$\mathrm{t} \quad=$ Tebal pemadatan; $(\mathrm{m})$

$\mathrm{v} \quad=$ Kecepatan rata - rata alat; $(\mathrm{km})$

$\mathrm{n} \quad=$ Jumlah lintasan; lintasan

$\mathrm{f}_{\mathrm{a}} \quad=$ Faktor efisiensi alat

$1000=$ Perkalian dari $\mathrm{km} \mathrm{ke}(\mathrm{m})$

Koefisien alat $/ \mathrm{m}^{3}:=\frac{1}{Q 3}$

4. Dump truck

Kapasitas produksi/jam,

$Q=\frac{V x F_{a} x 60}{D x T_{S}}$

Keterangan :

$\mathrm{Q}=$ Kapasitas produksi dump truck; $\left(\mathrm{m}^{3} / \mathrm{jam}\right)$

$\mathrm{V} \quad$ = Kapasitas bak; (ton)

$\mathrm{F}_{\mathrm{a}} \quad$ Faktor efisiensi alat

$\mathrm{F}_{\mathrm{k}} \quad$ = Faktor pengembangan bahan

$\mathrm{D}=$ Berat isi material; ton $/ \mathrm{m}^{3}$

$\mathrm{v}_{1} \quad=$ Kecepatan rata - rata bermuatan; (km/jam)

$\mathrm{v}_{2}=$ Kecepatan rata - rata kosong; $(\mathrm{km} / \mathrm{jam})$

Ts = Waktu siklus,

$$
T_{s}=\sum_{n-1}^{n} T_{n} \text { (menit). }
$$

$\mathrm{T} 1$ = Waktu muat: $=\frac{v \times 60}{D x Q_{\text {exv }}} \quad$ (menit)

$\mathrm{Q}_{\mathrm{exv}}=$ Kapasitas produksi backhoe $\mathrm{m}^{3} / \mathrm{jam}$

$\mathrm{T}_{2}=$ Waktu tempuh isi

$$
=\frac{L}{V_{1}} \times 60 \text {,(menit) }
$$

$\mathrm{T} 3=$ Waktu tempuh isi

$$
=\frac{L}{V_{2}} \times 60, \text { (menit) }
$$

$\mathrm{T}_{4}=$ Waktu lain - lain, (menit)

5. Water tanker truck

Kapasitas produksi/jam,

$Q=\frac{p_{a} \times F_{a} \times 60}{W_{c} \times 1000}$

Keterangan :

$\mathrm{V}=$ Volume tangki air; $\left(\mathrm{m}^{3}\right)$

$\mathrm{W}_{\mathrm{c}} \quad=$ Kebutuhan air $/ \mathrm{m}^{3}$ material padat; $\left(\mathrm{m}^{3}\right)$

$\mathrm{p}_{\mathrm{a}} \quad=$ Kapasitas pompa air; (liter/menit)

$\mathrm{F}_{\mathrm{a}} \quad=$ Faktor efisiensi alat

$1000=$ Perkalian dari $\mathrm{km}$ ke $\mathrm{m}$

6. Wheel loader

Kapasitas produksi/jam,

$Q=\frac{V \times F b \times 60}{T s}$

Keterangan :

$\mathrm{V} \quad=$ Kapasitas bucket $; \mathrm{m}^{3}$

$\mathrm{f}_{\mathrm{b}} \quad=$ Faktor bucket; $\mathrm{m} 3$

$\mathrm{F}_{\mathrm{a}} \quad$ Faktor efisiensi alat

Ts = Waktu siklus (memuat dan lain-lain) (standar 0.45 menit)

\section{d. Bagan Alir Penelitian}

Penelitian ini dimulai dengan membaca buku-buku referensi yang berhubungan dengan masalah penelitian. Langkah selanjutnya adalah mengumpulkan data di lapangan untuk menentukan penggunaan alat berat. Merencanakan pemakaian alat berat secara efisien agar (3.10)tidak terjadi keterlambatan dalam menyelesaikan proyek. Langkah terakhir adalah menarik kesimpulan dari hasil analisis yang diperoleh.

Langkah-langkah penelitian tergambar pada bagan (3.11)alir penelitian gambar 3.2.

ka , Optimalisasi Penggunaan Alat Berat pada Proyek Jalan Desa Sawah - Kayu Aro di Kabupaten Kampar 


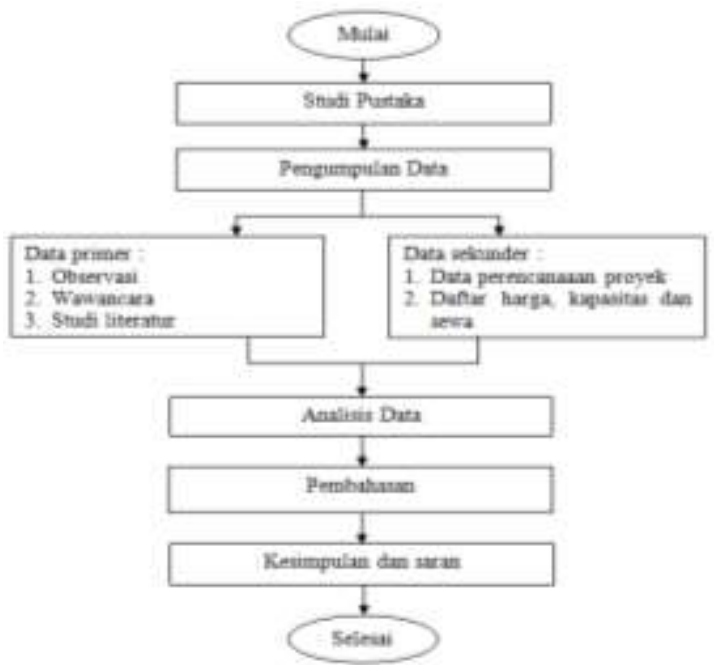

Gambar 2 Diagram alir penelitian

\section{HASIL DAN PEMBAHASAN}

\section{Analisis Data Penelitian}

a. Urutan kerja dan produktivitas alat berat

Kondisi medan area pekerjaan yang terdapat pada lokasi proyek adalah rawa dan bergambut. Sehingga memerlukan usaha penggalian dan pembuangan tanah terlebih dahulu ke area fasilitas pembuangan, kemudian di timbun kembali dengan tanah pilihan dari quarry, sesuai desain elevasi rencana. Pekerjaan yang akan dilakukan penimbunan dapat dilakukan dengan menggunakan alat berat backhoe di sini menggunakan model backhoe dan dump truck. Namun dikarenakan diklausul kontrak tidak terdapat pekerjaan galian maka perhitungan hanya dilakukan pada pekerjaan penimbunan.

Volume timbunan pilihan dari sumber galian $=$ $5.326,11 \mathrm{~m}^{3}$

1) Kapasitas produksi alat backhoe

Keterangan :

$\mathrm{V}=1,22 \mathrm{~m}^{3}$ (kapasitas bucket tabel2.10

$\mathrm{Fa}=0,83 \quad$ (faktor efisiensi alat tabel 2.3)

$\mathrm{Fb}=1,2 \quad$ (faktor bucket tabel 2.4)

$\mathrm{Fv}=0,9 \quad$ (faktor konversi galian tabel 2.5)

T1 = Lama menggali, memuat, (standar), (maksimum 0,32); (menit)

$\mathrm{T} 2$ = Lain - lain (standar), maksimum 0,10 ; (menit)

$\mathrm{Ts} 1=\mathrm{T} 1+\mathrm{T} 2=0,32+0,10=0,42$

Kapasitas produksi/jam, $Q=\frac{V x F_{b} \times F_{a} \times 60}{T_{s 1} x F v}$

$$
Q=\frac{1,22 \times 1,2 \times 0,83 \times 60}{0,42 \times 0,9}=192,88 \mathrm{~m}^{3} / \mathrm{jam}
$$

Produksi galian/hari $\mathrm{Q}_{\mathrm{t}}=\mathrm{T}_{\mathrm{k}} \mathrm{x} \mathrm{Q}=7$ jam/hari $\mathrm{x}$ $192,88 \mathrm{~m}^{3} / \mathrm{jam}=1.350,16 \mathrm{~m}^{3}$
Jadi waktu yang diperlukan oleh backhoe untuk pekerjaan penimbunan dengan volume sebanyak

$5.326,11 \mathrm{~m}^{3}$ :

$Q=\frac{5.326,11 \mathrm{~m}^{3}}{192,88 \mathrm{~m}^{3} / \mathrm{jam}}=27,2 \mathrm{jam}$

Jam kerja 7 jam/hari :

$Q=\frac{27,62}{7}=3,9$ hari $\approx 4$ hari

2) Kapasitas produksi alat dump truck

Keterangan :

$\mathrm{L}=35 \mathrm{~km} \quad$ (jarak rata-rata lokasi quarry dengan lokasi pekerjaan)

$\mathrm{V}=10$ ton (kapasitas bak tabel 2.16)

$\mathrm{Fa}=0,83 \quad$ (faktor efisiensi alat tabel 2.17)

$\mathrm{D}=1,650 \quad$ (berat isi material tabel 2.6)

$\mathrm{v} 1=40 \mathrm{~km} / \mathrm{jam}$ (kecepatan rata $\quad$ rata bermuatan tabel 2.18)

$\mathrm{v} 2=60 \mathrm{~km} / \mathrm{jam}$ (kecepatan rata - rata kosong tabel 2.18)

Qexv $=$ Kapasitas produksi backhoe $=192,88 \mathrm{~m} 3$

T4 = 2 menit (waktu lain - lain)

$\mathrm{T}_{1}=$ Waktu muat: $=\frac{V x 60}{D x Q_{e x v}}$ (menit)

$\mathrm{T}_{1}=\frac{10 \times 60}{1,650 \times 192,88}=1,89 \approx 2$ menit

$\mathrm{T}_{2}=$ Waktu tempuh isi $=\frac{L}{V_{1}} \times 60$ menit

$\mathrm{T}_{2}=\frac{35}{40} \times 60=52,5$ menit

$\mathrm{T}_{3}=$ Waktu tempuh kosong $=\frac{L}{V_{2}} \times 60$ menit

$\mathrm{T}_{3}=\frac{35}{60} x 60=35$ menit

Ts $=$ Waktu siklus, $T_{s}=\sum_{n-1}^{n} T_{n} \quad$ (menit)

$T_{s}=\sum_{n-1}^{n} T_{n}$ atau $=\mathrm{T}_{1}+\mathrm{T}_{2}+\mathrm{T}_{3}+\mathrm{T}_{4}$

$=2+52,5+35+2=91,5$ menit

Kapasitas produksi/jam, $Q=\frac{V x F_{a} x 60}{D x T_{s}}\left(\mathrm{~m}^{3}\right)$

$Q=\frac{10 \times 0,3 \times 60}{1,650 \times 91,5}=3,3 \mathrm{~m}^{3} / \mathrm{jam}$

$Q=\frac{5.326 .1 \mathrm{~m}^{3}}{3,3 \mathrm{~m}^{3} / \mathrm{jam}}=1613,98 \mathrm{jam}$

Jam kerja 7 jam/hari :

$Q=\frac{1.613,98 \mathrm{jam}}{7 \mathrm{jam} / \mathrm{hari}}=230$ hari untuk 1 (satu) dump

truck

Jika digunakan 8 unit dump truck maka :

$Q=\frac{230}{8}=28,83$ hari $\approx 29$ hari 
3) Kapasitas produksi alat motor grader

Untuk pekerjaan hamparan padat :

Keterangan :

$\mathrm{L}_{\mathrm{h}}=50 \mathrm{~m}$

(panjang hamparan)

$\mathrm{b}_{0}=0,30 \mathrm{~m}$

$\mathrm{t} \quad=0,15 \mathrm{~m}$

(lebar overlap)

(tebal hamparan padat diambil

$\mathrm{F}_{\mathrm{a}}=0,8$ $0.15 \mathrm{~m}$ )

(faktor efisiensi kerja tabel

2.12)

$\mathrm{n}=6$ lintasan (jumlah lintasan)

$\mathrm{N}=3$ lintasan (jumlah hamparan tiap lintasan)

$\mathrm{v}=12 \mathrm{~km} / \mathrm{jam}$ (kecepatan rata - rata tabel$$
\text { 2.11) }
$$

$\mathrm{b}=3,71 \mathrm{~m} \quad$ (lebar pisau efektif tabel 2.13)

$\mathrm{T}_{1}=0,25$ menit (waktu 1 kali lintasan :

$\left(\mathrm{L}_{\mathrm{h}} \times \mathrm{60}\right) /(\mathrm{v} \times 1.000)$

$\mathrm{T}_{2}=2$ menit $\quad$ (lain - lain)

$\mathrm{T}_{\mathrm{s} 3} \quad=$ waktu siklus, $T_{s}=\sum_{n-1}^{n} T_{n}$ (menit)

$T_{s}=\sum_{n-1}^{n} T_{n}$ atau $\mathrm{T}_{1}+\mathrm{T}_{2}=0,25+2=2,25$ menit

Kapasitas produksi/jam,

$Q=\frac{L_{h} x\left(N\left[b-b_{0}\right]+b_{0}\right) x t F_{a} \times 60}{T_{S} x N}$

$Q=\frac{50 x(3[3,71-0,30]+0,30) 0,15 \times 0,8 \times 60}{2,25 \times 3}=561,6 \mathrm{~m}^{2} / \mathrm{jam}$

2. Kapasitas produksi alat vibratory roller Keterangan :

$b_{\mathrm{e}}=2,03 \mathrm{~m}$

(lebar efektif pemadatan, lebar roda 0,1 , tabel 2,14 )

$\mathrm{t} \quad=0,15 \mathrm{~m} \quad$ (tebal pemadatan, diambil $0,15 \mathrm{~m})$

$\mathrm{v}=2 \mathrm{~km} / \mathrm{jam} \quad$ (kecepatan rata - rata alat tabel 2.14)

$\mathrm{n}=8$ lintasan (jumlah lintasan tabel

$$
\text { 2.14) }
$$

$\mathrm{f}_{\mathrm{a}}=0,83$ (faktor efisiensi alat tabel

2.3)

Kapasitas produksi/jam,

$Q=\frac{(\operatorname{bexv} \times 1.000) \times t \times f_{a}}{n}$

$Q=\frac{(2,3 \times 2 \times 1.000) \times 0,5 \times 0,83}{8}=63,19 \mathrm{~m}^{3} / \mathrm{jam}$

Koefisien alat $/ \mathrm{m}^{3}:=\frac{1}{Q}$

Koefisien alat $/ \mathrm{m}^{3} \frac{1}{Q}=\frac{1}{63,19}=0,01583$

5. Kapasitas produksi alat water tanker truck

Keterangan :

$\mathrm{V}=4 \mathrm{~m}^{3}$

(volume tangki

$\mathrm{W}_{\mathrm{c}}=0,07 \mathrm{~m}^{3}$ air, tabel 2.19)

(kebutuhan air $/ \mathrm{m}^{3}$

material padat) $\mathrm{p}_{\mathrm{a}}=100$ liter/menit (kapasitas pompa air,

tabel 2.19)

$F_{a}=0,83 \quad$ (faktor efisiensi

alat tabel 2.3)

Kapasitas produksi/jam, $Q=\frac{p_{a} x F_{a} x 60}{W_{c} \times 1.000}$

$Q=\frac{100 \times 0,83 \times 60}{0,07 \times 1.000}=71,15 \mathrm{~m}^{3}$

6. Kapasitas produksi alat wheel loader

Keterangan :

$\mathrm{V} \quad=3,2 \mathrm{~m}^{3} \quad$ (kapasitas bucket tabel 2.20)

$\mathrm{f}_{\mathrm{b}} \quad=1,1 \quad$ (factor bucket tabel 2.21)

$\mathrm{F}_{\mathrm{a}}=0,83 \quad$ (faktor efisiensi alat tabel 2.3)

Ts $=0,45$ menit (waktu siklus (memuat dan lain-lain) (standar 0,45 menit)

Kapasitas produksi/jam, $Q=\frac{V \times F b \times 60}{T s}$

$Q=\frac{3,2 \times 1,1 \times 60}{0,45}=469,34 \mathrm{~m}^{3}$

Tabel 18 Rekapitulasi biaya sewa alat berat berdasarkan hasil perhitungan dengan menggunakan rumus (PUPR 2016)

\begin{tabular}{|c|c|}
\hline Nama alat & $\begin{array}{c}\text { Biaya sewa } \\
\text { perjam/unit alat (Rp) }\end{array}$ \\
\hline Backhoe & 721.567 \\
\hline Dump truck & $468.892,3$ \\
\hline Motor grader & $841.555,35$ \\
\hline Vibratory roller & $528.697,56$ \\
\hline Water tanker truck & $499.862,3$ \\
\hline Whell loader & 1.041 .090 \\
\hline
\end{tabular}

(Sumber: Hasil perhitungan, 2018)

Tabel 19 Data-data alat berat dilapangan

\begin{tabular}{|c|c|}
\hline Alat berat & Jumlah \\
\hline Backhoe & 1 \\
\hline Dump truck & 8 \\
\hline Motor grader & 1 \\
\hline Vibratory roller & 1 \\
\hline Water tanker truck & 1 \\
\hline Whell loader & 1 \\
\hline
\end{tabular}

(Sumber : hasil survei dilapangan) 
Tabel 30 Rekapitulasi hasil perhitungan untuk kondisi lapangan

\begin{tabular}{|c|c|c|c|c|c|c|c|c|c|c|c|c|c|}
\hline \multicolumn{2}{|c|}{ 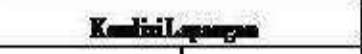 } & \multicolumn{4}{|c|}{$\mathrm{Mhej-I}$} & \multicolumn{4}{|c|}{ Pdajen $=\mathrm{B}=\mathrm{B}$} & \multicolumn{4}{|c|}{ Pd-jiman-A } \\
\hline Nhand Alt & 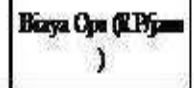 & Inath & 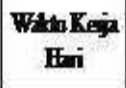 & jebije & 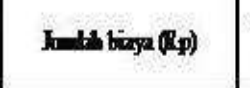 & Inim & $\begin{array}{c}\text { With Kajp } \\
\text { H. }\end{array}$ & jelajif & Inath binga (Ip) & Julatho: & $\begin{array}{c}\text { With Ke-j } \\
\text { Hin }\end{array}$ & jekejp & $h=1+\operatorname{ling}\left(I_{p}\right)$ \\
\hline Dasthos & 721567,0 & 1 & 29 & 7 & $1464 \pi: 101,0$ & - & - & - & - & - & - & - & - \\
\hline Dop That & 46292,0 & 8 & 29 & 7 & 7140100520 & $t$ & $\mathbf{x}$ & 7 & $62 \pi 7.18,20$ & 8 & 18 & 7 & $47264949: 40$ \\
\hline Mater Ginat & 41535 & 1 & 2 & 7 & $11 \pi L T 4,90$ & 1 & 2 & 7 & 11.7177490 & 1 & 1 & 7 & $5800 \% 1,5$ \\
\hline Fromokallor & 52269156 & 1 & 19 & 7 & $48111477 \%$ & 1 & 11 & 7 & 40.709.72,12 & 1 & 3 & 7 & 29601003,6 \\
\hline Fowlacts & 1041090,00 & - & - & - & - & 1 & $\mathbf{x}$ & 7 & $10.472 \operatorname{sen} 00$ & 1 & 18 & 7 & $19 L 17790,0$ \\
\hline 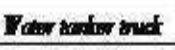 & 49919,90 & 1 & 19 & 7 & 45.487.49,90 & 1 & 10 & 7 & 94990961,00 & 1 & 7 & 7 & 24498252,0 \\
\hline & Sal mal & & 44 & & Rp $1.019999918,96$ & & 9 & & 99.67 .41622 & & $n$ & & 6598119:1,91 \\
\hline \multicolumn{13}{|c|}{ ItdI } & T. 264910330 \\
\hline & & & & & & & & & \multicolumn{2}{|l|}{ Italleritajp } & II: & \multicolumn{2}{|r|}{ 3Bab20Lri } \\
\hline
\end{tabular}

(Sumber: Hasil perhitungan, 2018)

Tabel 31 Rekapitulasi hasil perhitungan untuk kondisi alternatif I

\begin{tabular}{|c|c|c|c|c|c|c|c|c|c|c|c|c|c|c|}
\hline \multicolumn{2}{|c|}{ Alaneti I } & \multicolumn{4}{|c|}{$\mathrm{MH}=\mathrm{I}$} & \multicolumn{4}{|c|}{$P d \operatorname{den}=\mathrm{F}=\mathrm{B}$} & \multicolumn{5}{|c|}{ PdimaneA } \\
\hline$N=$ Alt & 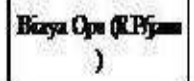 & hatit & $\begin{array}{c}\text { With } K_{\text {ej }} \\
\text { feni }\end{array}$ & $\begin{array}{l}\text { jembeji } \\
\text { eftuif }\end{array}$ & 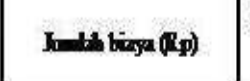 & but & With Kojp & interja & 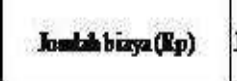 & Inathe nus & Win & joknja & & aldinga (Rp) \\
\hline Bacthos & 721567,00 & 1 & 15 & 7 & $75.76459 \mathrm{pm}$ & - & - & - & - & - & - & - & & - \\
\hline$D_{p}$ Thek & 465252,0 & 16 & 15 & 7 & 77779064po & 16 & 19 & 7 & 62.07.18sto & 16 & 9 & 7 & & 472649498,40 \\
\hline Hater Ginat & $441.555,9$ & 1 & 2 & 7 & $1 L \pi L T 74,90$ & 1 & 2 & 7 & $11 . \pi 177490$ & 1 & 1 & 7 & & $5.200287,45$ \\
\hline 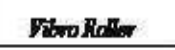 & 522697,6 & 1 & 19 & 7 & 48111477,6 & 1 & 11 & 7 & 40.709.72,12 & 1 & 8 & 7 & & $29.601060,5$ \\
\hline Flowlands & 1041090,00 & - & - & - & - & 1 & 19 & 7 & $9.779 .190,00$ & 1 & 9 & 7 & & $65528,670,0$ \\
\hline Font hader bux & 49985,90 & 1 & 13 & 7 & 45.487.49,90 & 1 & 10 & 7 & $94.990961,00$ & 1 & 7 & 7 & & $24493252, \pi$ \\
\hline & Suldibl & & 90 & & xate4921,16 & & $\mathbf{x}$ & & 264.9220622 & & 18 & & Kp & 5xe23911,91 \\
\hline \multicolumn{13}{|c|}{ Itw } & Fi & 2132005sespe \\
\hline \multicolumn{13}{|c|}{ 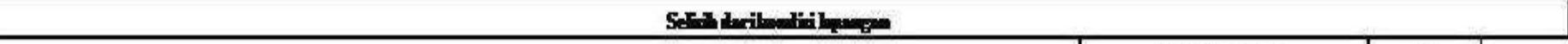 } & E. & 2anum,an \\
\hline & & & & & & & & & \multicolumn{2}{|l|}{ Itallmariterje } & 7 & \multicolumn{3}{|c|}{ 2Bdal-14hri } \\
\hline
\end{tabular}

(Sumber: Hasil perhitungan, 2018) 


\section{PENUTUP}

\section{Kesimpulan}

Berdasarkan hasil analisis dan perhitungan maka dapat ditarik kesimpulan bahwa hasil perhitungan dan pembahasan pada alternatif II optimal dari segi biaya yaitu selisih dengan kondisi lapangan Rp. $182.570 .575,50$ dan dari segi waktu yaitu 62 hari lebih cepat dari kondisi lapangan maka untuk proyek peningkatan jalan Desa Sawah-Kayu Aro di Kabupaten Kampar direkomendasikan digunakan alternatif II dengan waktu 48 hari (1 Bulan 18 hari) dan biaya sebesar Rp. 2.454.248.807,59.

Tabel 33 Komposisi penggunaan alat berat

\begin{tabular}{|c|c|c|c|c|c|}
\hline No & Kondisi & Jenis Alat & Tipe Alat & $\begin{array}{l}\text { Waktu } \\
\text { (hari) }\end{array}$ & $\begin{array}{c}\text { Biaya } \\
\text { (Rp) }\end{array}$ \\
\hline 1 & \multirow{6}{*}{$\begin{array}{l}\text { Alternatif } \\
\text { II }\end{array}$} & Backhoe & PC 200 & \multirow{6}{*}{48} & \multirow{6}{*}{$\begin{array}{c}2.454 .248 \\
.807,59\end{array}$} \\
\hline 2 & & Dump truck & FE 74 & & \\
\hline 3 & & Motor grader & GD535-5 & & \\
\hline 4 & & Vibratory roller & SV 512 & & \\
\hline 5 & & Water tanker truck & FE 74 & & \\
\hline 6 & & Whell loader & WA 320 & & \\
\hline
\end{tabular}

(Sumber: Hasil perhitungan, 2018)

\section{Saran}

Perencanaan penggunaan alat berat pada pekerjaan timbunan pilihan, pekerjaan lapis pondasi agregat kelas B (LPA-B) dan pekerjaan lapis pondasi agregat kelas A (LPA-A) yang meliputi efisiensi kerja biaya dan waktu akan berdampak pada kelancaran pekerjaan di lapangan. Terkadang, pelaksanaan pekerjaan di lapangan berbeda dengan yang direncanakan. Banyak faktor yang menyebabkan terjadinya perbedaan tersebut seperti jarak lokasi proyek dengan quarry/stock pile serta cuaca yang kurang mendukung, tingkat kesulitan kerja di lapangan. Sehubungan dengan alat berat yang akan dipergunakan pada proyek peningkatan jalan Desa Sawah-Kayu Aro di Kabupaten Kampar yang jarak lokasi proyek dengan quarry/stock pile berjarak relatif jauh, ada beberapa saran yang perlu dikemukakan, yaitu :

1. Bagi kontraktor yang hendak melaksanakan proyek, hendaknya memperkirakan siklus kerja alat yang efisien dan menghitung secara cermat biaya yang akan dikeluarkan agar biaya yang dikeluarkan dapat ditekan sekecil mungkin melalui efisiensi kerja alat yang digunakan.

2. Pada pekerjaan jalan ini dibutuhkan operator alat berat yang mampu mengopersikan alat berat baik dan mengetahui teknis pelaksanaan masing masing pekerjaan.

3. Pemilihan alat berat dan manajemen waktu perlu diperhatikan, karena sangat berkaitan erat untuk mendapatkan hasil yang optimal dalam pelaksanaan proyek peningkatan jalan Desa Sawah-Kayu Aro di Kabupaten Kampar, sehingga pekerjaan dapat tepat waktu dan sesuai dengan jadwal yang terlah ditentukan.

\section{DAFTAR PUSTAKA}

[1] Farida I. 2013. Perbandingan Biaya dan Waktu Pemakaian Alat Berat Buldozer dan Backhoe di Bandingkan Dengan Backhoe Loader Pada Pembangunan Peternakan Ayam Dayeuh Manggung. Jurnal Teknik Sipil 11(1): $1-10$.

[2] Hardiyatmo HC. 2012. Mekanika Tanah 1. Yogyakarta : Gadjah Mada University Press.

[3] Indrayani. 2010. Pemindahan Tanah Mekanis dan Alat Berat. : Politeknik Negeri Sriwijaya.

[4] Kholil A. 2012. Alat Berat. Bandung : PT. Remaja Rosdakarya.

[5] Maddeppungeng A. 2013. Analisis Produktivitas Alat Berat pada Proyek Pembangunan Pabrik Krakatau Posco Zone IV di Cilegon. Jurnal Teknik Sipil 4(2): 91 103.

[6]Mitsubishi.2018.KaroseriMitsubishiColtDieselFE 74.https://mobiltruckmitsubishi.wordpress .com/info-harga-karoseri/dump-truk3way-fe-74-hd/. (03 Juli 2018).

[7]Mitsubishi.2018.KaroseriMitsubishi Fuso 10 Roda Tipe FN 527 ML http://dealertruck-

mitsubishi.blogspot.com/2010/05/speckar oseri-dump-truck.html. (03 Juli 2018)

[8]Mitsubishi.2018.KaroseriWaterTankerTruck4000 LiterColtDieselhttps://mobiltruckmitsubis hi.wordpress.com/info-hargakaroseri/tangki-vacum-4000-liter-coltdiesel/. (03 Juli 2018).

[9]Nofrianto H. 2015. Optimalisasi Alat Berat Pada Pekerjaan Timbunan Proyek Pembangunan Jalan Lingkar Kota Bangkinang Kabupaten Kampar (Tugas Akhir). Pekanbaru : Program Studi S1 Teknik Sipil, Universitas Lancang Kuning.

[10]Oetomo W. 2014. Perencanaan Pe naan Alat Berat dan Biaya pada .....bangunan Sekolah Terpadu Samarinda. Jurnal Teknik Sipil 7(2): 115 - 128.

[11]Polmas. 2014. Jalan Perubahan Untuk Indonesia Yang Berdaulat, Mandiri dan Berkepribadian.VisiMisi,danProgramAksi .https://polmas.wordpress.com/2014/09/2 0/visi-misi-dan-program-aksipemerintahan-joko-widodojusuf-ka0lla2014-2019/. (03 Juli 2018). 